\title{
Hemşirelikte Yeni Bir Alan: Adli Hemşirelik
}

\section{A New Field in The Discipline of Nursing: Forensic Nursing}

\author{
Sunay Fırat ${ }^{1}$, Sevi Ünal ${ }^{2}$, Çiğdem Yalçın Geleş ${ }^{2}$ \\ ${ }^{1}$ Çukurova Üniversitesi Sağlık Bilimleri Fakültesi, Psikiyatri Hemşireliği Anabilim Dalı, Adana \\ ${ }^{2}$ Çukurova Üniversitesi Sağlık Bilimleri Fakültesi, Hemşirelik Anabilim Dal, Yüksek Lisans Öğrencisi, Adana
}

\section{Özet}

Sağlık çalışanları, günümüzde hem mağdurların hem de faillerin muayenesi, delillerin belirlenmesi, toplanması, paketlenmesi ve korunmasında kullanılacak yöntemler konusunda yeterli bilgiye sahip değillerdir.

Adli olgularda bireyi ilk gören, ailesi ya da yakınlarıyla ilk iletişime giren, muayene sırasında eşyalarına dokunan ve bireyden alınan laboratuar örnekleri ile ilk temas eden kişiler genellikle ekipteki hemşirelerdir.

Hemşirelik bilgi ve deneyimlerinin yargının hizmetine sunulması ile ortaya çıkan ve giderek gelişen bir uzmanlık alanı adli hemşireliktir. Adli hemşirelik, hemşirelik temel eğitiminin, şiddet, travma ve diğer suç olgularının failleri ile travma ve/veya ölüm olgularındaki kurbanların muayenesi ve bilimsel olarak araştırılmasına katkı sağlayan ekibin bir parçasıdır.

$\mathrm{Bu}$ çalışmanın amacı, hemşirelikte yeni bir alan olan adli hemşirelik alanına dikkatlerin çekilmesi, dünyadaki ve Türkiye'deki durumu, adli hemşireliğin standartları ve çalışma alanları ile ilgili temel bilgilerin ele alınmasını sağlamaktır.

Adli hemşire, dünyada son otuz yılda şiddet, yaralanmalar, aile içi şiddet ve çocuk istismarının tanımlanması ve bakımı gibi durumlarda, kanıt toplamak, tarafsız bir şekilde yönlendirme ve krize müdahale oluşturan ekibin bir üyesidir. Adli hemşireler, mesleklerini geliştirmek için lisansüstü hemşirelik eğitimi, bilirkişilik, savunan ve karar veren kişilere destek olmak ve hemşirelik uygulama standartlarını artırmak suretiyle hasta bakımında yer alırlar.

Dünyada yeni bir alan olan adli hemşirelik ülkemizde giderek gelişen çok yeni bir hemşirelik uzmanlık alanıdır.

Ülkemizde görev tanımı yapılmış, yasal olarak tanımlanmış adli hemşireler bulunmamaktadır. Adli olguların değerlendirilmesi çoğunlukla özel eğitim almamış hemşireler tarafından yapılmaktadır. Bu nedenlerle ülkemizde, ulusal ve uluslararası ölçekte etik olarak adli olgulara bütüncül hemşirelik yaklaşımını uygulayabilecek, profesyonel liderlik ve sorun çözme becerilerine sahip uzman adli hemşireler yetiştirilmesine gereksinim duyulmaktadır.

Anahtar Kelimeler: Adli Hemşirelik, Hemşirelik, Adli Bilimler, Türkiye.

\section{Giriş}

Suç ve şiddet olaylarının arttığı günümüzde hem mağdurların hem de faillerin ilk karşılaştıkları sağlık ekibi üyeleri hemşirelerdir. Bu nedenle adli tıp konularında uzmanlık eğitimi ve özel eğitim almış adli hemşirelerin adli

Sorumlu Yazar: Yrd. Doç. Dr. Sunay Frrat

Çukurova Üniversitesi, Sağlık Bilimleri Fakültesi, Hemşirelik Bölümü, Adana E-mail: sunayfirat@gmail.com

\section{Abstract}

Health professionals generally lack adequate knowledge about the examination of victims and suspects, and the methods used for the identification, collection and preservation of legal evidence.

In most forensic cases, nurses are the first persons in a medical team to see the victims or suspects, to contact their family or relatives, to handle their items and belongings during examination, and to collect laboratory samples.

Forensic nursing is a new and gradually developing area of specialization that supports the judiciary through the knowledge and experiences associated with nursing. Forensic nurses contribute to the medical team by applying their basic nursing knowledge to the examination and scientific evaluation of victims and perpetrators in crimes involving violence, trauma and/or death.

The aim of this study was to draw attention to forensic nursing as a new field of nursing; to review the current state of forensic nursing in Turkey and around the world; and to provide a general overview of its standards and areas of activity.

Over the past 30 years, forensic nurses in medical teams around the world have been tasked with identifying and providing care for cases of injury, domestic violence and child abuse, and also with collecting evidence, guiding judicial processes as an impartial contributor, and responding to emergencies. After taking the necessary postgraduate trainings for professional development and improving their knowledge on standard nursing applications, nurses can provide patient care as forensic nurses while also supporting expert witnesses, defendants and court authorities in legal cases.

Forensic nursing, which is relatively new discipline around the world, is also a new and developing field in Turkey.

In Turkey, the job definition for forensic nurses has not yet been legally defined; consequently, most forensic cases are still examined by nurses with no special forensic training. For this reason, there is a requirement in Turkey for specialized forensic nurses with professional leadership and problem-solving skills, who can effectively apply holistic nursing approaches to forensic cases in accordance with national and international ethical requirements.

Keywords: Forensic Nursing, Nursing, Forensic Sciences, Turkey.

ekip içinde birçok adli olayın çözümüne katkı sağlayacakları düşünülmektedir $(1,2)$. Hemşireler karşılaştıkları adli olgularda bireyi ilk gören, ailesi ya da yakınlarıyla ilk iletişime giren, muayene sırasında eşyalarına dokunan ve bireyden alınan laboratuar örnekleri ile ilk temas eden kişilerdir (3).

Dünyada, Dr. Harry McNamara (1987), adli tıp bilgisi yetersiz olan sağlık personellerinin bilimsel araştırma sonuçlarını ve uygun şekilde kanıt toplanmasını olumsuz yönde etkilediğini belirterek, adli hemşireliğin klinik 
hemşirelik uygulamaları içinde yeni bir alan olarak yer alması gerektiğini ileri sürmüştür $(2,4,5)$. Uluslararası Adli Hemşireler Birliği'nin (IAFN) tanımına göre; adli hemşirelik, sağlık ve adli sistemlerin kesiştiği genel hemşirelik uygulamalarıdır (6). Adli Hemşirelik, Adli Bilimlerin çalışma alanlarından birisidir (3).

21. yüzyılda, adli hemşirelik eğitimine yönelik yenilikçi bir hareket sonrası diploma, lisans ve doktora seviyelerinde uluslararası yerini alması beklenmektedir (2). Hukukun tıpla ilgili konularını araştıran adli bilimler, başta adli patoloji, adli toksikoloji, adli genetik ve adli psikiyatri olmak üzere tıp hukuku, adli mühendislik ve adli hemşirelik gibi birçok disiplini içermektedir $(7,8)$.

$\mathrm{Bu}$ çalışmanın amacı, hemşirelikte yeni bir alan olan adli hemşirelik alanına dikkatlerin çekilmesi, dünyadaki ve Türkiye'deki durumu, adli hemşireliğin standartları ve çalışma alanları ile ilgili temel bilgilerin ele alınmasını sağlamaktır.

\section{Adli Hemşirelik Tanımı ve Tarihçesi}

Adli hemşire, şiddet, yaralanmalar, aile içi şiddet ve çocuk istismarının, tanımlanması ve bakımı gibi durumlarda, kanıt toplamak, tarafsız bir şekilde yönlendirme ve krize müdahale oluşturur (9).

IAFN'a göre, Adli hemşirelik; hemşirelik temel eğitiminin, şiddet, travma ve diğer suç olgularının failleri ile travma ve/veya ölüm olgularındaki kurbanların muayenesi ve bilimsel olarak araştırılmasına katkı sağlar.

Bir diğer tanımda ise Adli hemşirelik, "hemşirelik biliminin yasal prosedürlere uygulanması olup, adli bilimlerin, hemşirelerin eğitimleri ile birleştirilerek, bilimsel araştırmalara, yaralı veya ölü mağdurların muayenesine, suç, şiddet, kriminal aktivite ve travmatik kaza faillerinin rehabilitasyonuna uygulanması' şeklinde de ifade edilmektedir (3).

Adli hemşireliğin tarihsel gelişimi incelendiğinde hemşirelerin XVIII. yüzyıldan itibaren adli olaylarla karşılaştıkları bildirilmektedir. Adli hemşirelik, ilk olarak Cinsel Saldırı Alanında Çalışan Adli Hemşireler tarafından (The Sexual Assault Nurse Examiner, SANE), delil toplama süreci, teknik beceri ve bulguların yorumlanması için hemşireler tarafından 1970'li yılların başında organize edilmiştir. Ancak ilk olarak 1987 yılında Dr. Harry McNamara, adli tıp bilgisi yetersiz olan sağlık personelinin bilimsel araştırma sonuçlarını ve uygun şekilde kanıt toplanmasını olumsuz yönde etkilediğini belirterek, adli hemşireliğin klinik hemşirelik uygulamaları içinde yeni bir alan olarak yer alması gerektiğini ileri sürmüştür $(2,4,5)$.

Adli hemşirelik 1995’te Amerikan Hemşireler Birliği (American Nurses Association) tarafından hemşireliğin bir uzmanlık dalı olarak tanınmış ve 1997'de kapsam ve standartları onaylanmıştır. Başta Amerika Birleşik Devletleri olmak üzere birçok ülkede 1990'lı yılların ortalarında lisans ve yüksek lisans programlarında adli hemşirelik derslerine yer verilmeye başlanmıştır $(2,10,11)$.

\section{Adli Hemşireliğin Dünya'daki Yeri}

Adli hemşirelik, hemşirelik bilgi ve deneyimlerinin yargının hizmetine sunulması ile ortaya çıkan ve giderek gelişen bir uzmanlık alanıdır. Amerika Birleşik Devletleri (ABD), İngiltere, Almanya, Avustralya, Kanada, Güney Afrika, Japonya, Singapur, Suudi Arabistan gibi pek çok ülkede adli hemşire yargıya destek personel olarak görev yapmaktadır. Başta adli tıp olmak üzere seroloji, toksikoloji, narkotik gibi alanlarda suçun aydınlatılması ve suçlunun tespit edilmesi suretiyle adli hataları önleme konusunda, ayrıca ceza hukuku, ceza muhakemesi hukuku ve kriminoloji ile adli tıp uygulamalarının örtüştüğü alanlarda özel olarak eğitilen hemşireler tıp ve hukuk uygulamalarındaki parametrelere bağlı olarak hizmet vermektedirler(12).

\section{Adli Hemşireliğin Türkiye'deki Yeri}

Ülkemizde adli hemşirelik yeni bir kavram olmakla birlikte günümüzde gelişmesini sürdürmektedir (11). Ülkemizde görev tanımı yapılmış, yasal olarak tanımlanmış adli hemşireler bulunmamaktadır. Bu nedenle adli olguların değerlendirilmesi çoğunlukla özel eğitim almamış hemşireler tarafından yapılmaktadır (3). Uzman olmayan hemşireler kanıtları tanımlama, toplama ve saklama prosedür ve teknikleri bilmemesi sonucu, tedavi ve bakım sırasında kanıtların gözden kaçırılmasına, kaybedilmesine ya da yok edilmesine-neden olmaktadır (13).

İlk olarak 2004 yılında Ankara Üniversitesi, Tıp Fakültesi, Adli Tıp Anabilim Dalı bünyesinde başvuranların sağlıklı bir ortamda fizik muayenelerinin sağlanması, laboratuar tetkiklerinin yapılabilmesi için uygun örneklerin alınması, eğitim programlarının düzenlenmesi, bu alandaki bilgi ve becerilerin diğer hemşirelere de aktarılması ve adli hemşirelik kavramının rutin uygulamalara yerleştirilerek temel prensiplerinin oluşturulması amaçlanarak “Adli Hemşirelik Birimi” kurulmuştur $(12,13)$.

Hacettepe Üniversitesi, Hemşirelik Yüksekokulu ve Adli Bilimciler Derneği işbirliği ile sertifikalı kurslar düzenlenmeye başlanmıştır. Alınan olumlu geribildirimler ve yoğun istek üzerine kurs tekrarlama kararı alınmış ve 25-28 Mart 2004 tarihleri arasında II. Adli Hemşirelik Kursu düzenlenmiştir (12). Tıp ve delillerin tespiti gibi birçok konuda eğitim alan ekip, özellikle cinsel suçlar ve çocuk istismarı ile ilgili olaylarla ilgilenmektedirler (11). 


\section{Adli Hemşireliğin Standartları ve Kapsamı}

Amerikan Hemşireler Birliği (ANA) ve Uluslararası Hemşireler Birliği (IAFN) 2009'da, Adli Hemşireliğin uygulama standartları ve kapsamı, değerlendirme, tanı, sonuçlar ve işlemlerinden oluşan hemşirelik süreçleri üzerine uygulama standartlarını oluşturmuşlardır.

Buna göre adli hemşire;

口Adli Hemşirelik uygulamaları eğitimi, mesleki uygulama ve değerlendirme, işbirliği, etik araştırmalar, kaynak kullanımı ve liderlik niteliklerini kapsar ve adli hemşirelik uzmanlık alanının tanınmasını ve gelişimini sağlar.

$\square$ Özellikle adli hemşireliğin doğası ve diğer profesyonel uygulamalar ile ortaklığı ve yasal sonuçlara etkisi, adli hemşirelik uygulamalarının güncel olmasını zorunlu kılar.

$\square$ Mesleklerini geliştirmek için lisansüstü hemşirelik eğitimi, bilirkişilik, savunan ve karar veren kişilere destek olmak ve hemşirelik uygulama standartlarını artırmak suretiyle hasta bakımında yer alırlar.

$\square$ Toplumsal olaylarda ve yasalarla bağlantılı sağlık hizmetlerinde; travmanın ve şiddetin önlenmesinde, mağdur, fail ve hükümlü haklarının korunmasında, internet suçlarında, biyo-terörizimde, kitle facialarında aktif rol alırlar.

$\square$ Sağlık hizmetlerinde ve sağlığın geliştirilmesinde, yerel, ulusal ve evrensel düzeyde adli tıp konularında yer alırlar (6).

\section{Adli Hemşirelerin Çalışma Alanları \\ Klinik Adli Hemşirelik}

Travma sonrası acil servisler başta olmak üzere sağlık kuruluşlarına gelen ya da getirilen kişilere müdahale eden ekipte yer alan hemşireler; ister kurban isterse fail olsun tıbbi kayıtların doğru ve eksiksiz olarak yapılması, kişinin üzerindeki giysilerin uygun şekilde çıkarılıp saklanması, kişiden alkol, uyutucu-uyuşturucu ve benzeri maddelerin tespiti için örnek alınması ve çeşitli suçlarda gerek mağdur gerekse failden uygun bir şekilde biyolojik delillerin toplanması sürecinde görev almalıdırlar (4).

\section{Cinsel Saldırı Muayenesinde Adli Hemşirelik}

Cinsel saldırı mağdurlarının fiziksel değerlendirilmesi, fiziksel ve biyolojik delillerin toplanması, cinsel yolla bulaşan hastalıkların değerlendirilmesi için gerekli testlerin yapılması, tedavi ve önerilerde bulunulması, tecavïze bağlı oluşabilecek olası gebeliklerin önlenmesi, destek amaçlı tedavilerin uygulanması, duygusal travmanın önlenmesi, mağdurun izlemini ve rehabilitasyonunu ve adli rapor yazımını sağlamakta ve gerektiğinde tanık olarak görev almaktadır (13).

\section{Adli Psikiyatri Hemşireliği}

Suç işleyen ve ruhsal açıdan yeterliğinin olup olmadığ bilinmeyen ve bu nedenle herhangi bir ruhsal bozukluğunun olup olmadığını değerlendirmek amacıyla ya da suç işleyen, ruh sağlığı bozuk olduğu için fiziksel ve ruhsal sağlık bakım ve tedavilerinin yapılması için yüksek/orta veya düşük güvenlikli bir sağlık kuruluşluna yatışı yapılan davalı bireyler "adli psikiyatri hastası" olarak karşımıza çıkmaktadır ${ }^{14}$. Psikiyatri hemşireliği bütünsel bir bakımdır; hastanın fiziksel, psikolojik, sosyal, ruhsal ve kültürel durumunu da kapsamaktadır. Hastaları, sosyal ve pratik yaşam becerilerini geliştirmeleri için destekleme, anlayışlı olma ve teşvik etmek gerekmektedir (4).

\section{Olay Yeri İncelemesinde Adli Hemşirelik}

Adli hemşireler Kanada ve Kuzey Amerika'daki ölüm araştırmalarında 1970'lerden beri yer almaktadır. Adli tıp ölüm araştırmaları sistemlere göre değişmekle birlikte adli hemşirelerin kayıt tutma, konuya ilişkin bilgi sahibi olma ve hemşirelik tutumu politikası olay yerinin fotoğraflanması, adli raporun hazırlanması, adli ekip üyeleri arasında bilgi akışının sağlanması ölenin yakınlarına bilgi ve destek verilmesini sağlamakta ve gerektiğinde tanıklık yapmak gibi kapsayan görevleri olduğu büyük ölçüde kabul edilmektedir $(11,12)$.

\section{Adli Geriatri Hemşireliği}

$\mathrm{Bu}$ alanda çalışan hemşire, geriatri kliniklerinde yaşlı istismarı gibi olaylarda, vakalarda fiziksel değerlendirme yapılması ve rapor tutulmasında görev yapmaktadır (13). Adli geriatri hemşireleri; istismar ve ihmale neden olabilecek durumlarda yaşlı bireylerin insani haklarını korumakla görevlidirler. Bakımevleri ya da sığınma evleri genellikle bu alandaki hemşireleri istihdam eder. Bu hemşireler bilgi ve deneyimlerini daha çok yaşlıların istismara ve ihmale uğradığı olaylarda kullanırlar (12).

\section{Adli Pediatri Hemşireliği}

Adli pediatri hemşireleri çocuklara bakım verirler ve istismar, ihmal ve insan hakları ile ilgili konuları incelerler. Bu alanda çalışan hemşire, çocuk istismarı ve ihmali olaylarının kabulü ve değerlendirilmesi, tedavisi, koruyucu hizmet veren birimlere yönlendirilmesi, aile içi şiddet, hırpalanmış çocuk sendromu ve ani çocuk ölümü gibi olayların olma ihtimallerinin incelenmesini, mağdurun izlemini ve rehabilitasyonunu sağlamakta ve gerektiğinde tanık olarak görev almaktadır $(11,12)$.

\section{Adli Hemşirenin Görev ve Sorumluluk- lar1}

Son yıllarda şiddet olaylarının sıklığı artmaktadır. Bu artış acil servislerde çalışan sağlık profesyonellerinin konu ile ilgili uzmanlar (Adli tıp uzmanları, kolluk kuvvetleri vs.) gelene kadar saklama, koruma, kayit tutma ve kanit toplama durumlarında önemini artırmıştır (14,15). Hastanelerin acil tedavi ünitelerine başvuran adli olgular ile ilk temas edenler bu birimlerde görevli hekim, hemşire ve diğer sağlık personelidir 
(16). Bu durum sağlık profesyonellerinin yasal olarak görev ve sorumluluklarını arttırmaktadır.

Türk Ceza Kanunu'nun (TCK) "Sağlık Mesleği Mensuplarının Suçu Bildirmemesi" başlı̆̆ 1 ile düzenlenen 280. maddesinde "Görevini yaptığı sırada bir suçun işlendiği yönünde bir belirti ile karşılaşmasına rağmen, durumu yetkili makamlara bildirmeyen veya bu hususta gecikme gösteren sağlık mesleği mensubu cezalandırılır." ifadesi yer almaktadır $(16,17)$.

Hemşirelik Kanunu'nda Değişiklik Yapılmasına Dair Kanun'un (Kanun No. 5634 RG: 2.5.2007/26510) 4. maddesine göre: "Hemşireler; tabip tarafından acil haller dışında yazılı olarak verilen tedavileri uygulamak, her ortamda bireyin, ailenin ve toplumun hemşirelik girişimleri ile karşılanabilecek sağlıkla ilgili ihtiyaçlarını belirlemek ve hemşirelik tanılama süreci kapsamında belirlenen ihtiyaçlar çerçevesinde hemşirelik bakımını planlamak, uygulamak, denetlemek ve değerlendirmekle görevli ve yetkili sağlık personelidir. Ayrıca aile hekimliği uygulamasına ilişkin kanun hükümleri ile bu Kanuna dayanılarak yürürlüğe konulan mevzuattaki görevleri de yaparlar." Adli hemşire bu kanun kapsamında, adli hemşirelik sürecini kullanarak adli hastanın bakım ve tedavisini gerçekleştirebilmekte ve adli sürecin hemşirelik boyutunun gerçekleştirilmesinde adli ekiple işbirliği içerisinde görev yapabilmektedir $(11,18)$.

\section{Tartışma ve Sonuç}

Suç ve şiddet olaylarının arttığı günümüzde hem mağdurların hem de faillerin ilk karşılaştıkları sağlık ekibi üyeleri hemşirelerdir. Bu nedenle adli tıp konularında uzmanlık eğitimi ve özel eğitim almış adli hemşirelerin adli ekip içinde birçok adli olayın çözümüne katkı sağlayacakları düşünüilmektedir $(1,2)$.

Ülkemizde suça maruz kalmış bireylerin saptanması, şiddete bağlı yaralanmaların ve ölümlerin önlenmesi ve istismar olgularının erken araştırılarak şiddet döngüsünün durdurulması gerekmektedir. Bu uygulamaların ülkemizde hayata geçirilebilmesi için Türkiye genelinde lisans programında hemşirelik öğrencilerine adli hemşirelik dersi verilmesi, adli hemşirelik gereksinimlerini karşılamak için hemşirelik yüksek lisans ve doktora programlarının açılması, hastanede çalışan hemşirelerin hizmet içi programlarına adli hemşirelik başlı̆̆ının eklenmesi ve sertifikasyon sağlanmalıdır. Adli konularda görev yapan sağlık kuruluşlarında “Adli Hemşirelik Birim”lerinin oluşturulması önerilebilir (3). Ülkemizde adli hemşirelerin, rolleri ve çalışma alanları ile ilgili geniş bir çalışmaya, değerlendirmeye ve tanımlamaya ihtiyaçları vardır.
Sonuç olarak, adli hemşireliğin ilke ve kavramlarının daha kapsamlı farkına varılması ve kavranması ile bilgi ve becerilerin kapsamının geliştirilmesi, ulusal ve uluslararası ölçekte etik, adli olgulara bütüncül hemşirelik yaklaşımını uygulayabilecek, profesyonel liderlik ve sorun çözme becerilerine sahip uzman adli hemşireler yetiştirilmesine gereksinim duyulmaktadır.

\section{Kaynaklar}

1. Lynch VA. Forensic nursing science: Global strategies in health and justice, Egyptian Journal of Forensic Sciences 2011;69-76.

2. Wilkinson- Kent A. Forensic nursing educational development: an integrated review of the literature, Journal of Psychiatric and Mental Health Nursing 2011;18:236-246.

3. Şentürk S, Büyükaslan B. Hemşirelik son sınıf öğrencilerinin adli hemşirelik konusundaki bilgi ve görüşlerinin belirlenmesi, Bozok Tip Dergisi 2013;3(3):19-26.

4. Eşiyok B, Hancı İH, Özdemir Ç, Yelken N, Zeyfeoğlu Y. Adli hemşirelik, Sted 2004;13(5):169-171.

5. Simmons B. Graduate forensic nursing education how to better educate nurses to care for this patient population, Nurse Educator 2014;39(4):184-187.

6. Constantino R, Crane P, Young S. Forensic nursing evidence based principles and practice, Chapter one Fundamentals of contemporary forensic nursing practice,education and research.Philadelphia: F.ADavis Co, 2013;3-26.

7. Koç S, Biçer Ü. Adli tıbbın tarihsel gelişimi, Türkiye'deki yapılanması ve sorunları. Klinik Gelişim. 2009;22 (Adli Tıp Özel Say1s1):1-5

8. Kent-Wilkinson A. Spotlight on forensic nursing, International Journal of Trauma Nursing 1999;5:106-109.

9. Gökdoğan MR, Erkol Z. Forensic nursing in Bolu, Turkey: A Survey, Journal of Clinical Forensic Medicine 2005;12:14-17.

10. Lynch VA. Evolution of forensic nursing science. Chapter one. Forensic Nursing Science, 2nd. Edition 2011;1-16. Erişim: 3 Eylül 2015.

11. Çilingir D, Hintistan S. Adli hemşireliğin kapsamı ve yasal boyutu. Hemşirelikte Eğitim ve Araştırma Dergisi 2012; 9(1): 10-15.

12. Çevik Akköz S, Başer M. Adli hemşirelik ve çalışma alanları. Sağlık Bilimleri Dergisi 2012;21(2):143-152.

13. Lynch V.A. Forensic nursing a handbook for practice. St. Louis: Elsevier Mosby 2006. Erişim: 20 Nisan2015.

https://books.google.com.tr/books?id=APgVX1WcuYcC\&prints

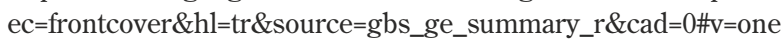
page\&q\&f=false

14. Arabacı LB, Çam MO. Psikiyatri hastalarına yönelik hemşire tutum ölçeği geliştirme, Nöropsikiyatri Arşivi 2011;48: 175-83.

15. İlçe A, Yıldız D, Baysal G, Özdoğan F, Taş F. Acil servislerde çalışan sağlık bakım personelinin adli olgularda delillerin korunması ve saklanmasına yönelik bilgi ve uygulamalarının incelenmesi. Ulusal Travma ve Acil Cerrahi Dergisi 2010;16(6):546-551.

16. Karadayı B, Kolusayın ÖM, Kaya A, Karadayı Ş. Acil tedavi birimlerinde adli olgudan biyolojik materyal alınması ve gönderilmesi. Marmara Üniversitesi Tip Fakültesi Dergisi 2013;6:111-117.

17. http://www.resmigazete.gov.tr/eskiler/2007/05/20070502-3.htm Erișim Tarihi: 5Ekim 2015.

18. https://www.tbmm.gov.tr/kanunlar/k5237.html Erişim Tarihi: 5 Ekim 2015. 